Research, Society and Development, v. 10, n. 8, e0110816429, 2021

(CC BY 4.0) | ISSN 2525-3409 | DOI: http://dx.doi.org/10.33448/rsd-v10i8.16429

\title{
Tumor venéreo transmissível em cavidade abdominal de cadela: Relato incomum
}

\author{
Transmissible veneral tumor in a dog's abdominal cavity: Uncommon report \\ Tumor venéreo transmisible em la cavidad abdominal de un perro: Informe poco común
}

Recebido: 23/05/2021 | Revisado: 30/05/2021 | Aceito: 02/07/2021 | Publicado: 03/07/2021

\author{
Aline Groth \\ ORCID: https://orcid.org/0000-0002-3177-6851 \\ Universidade Estadual de Londrina, Brasil \\ E-mail: aline_groth@hotmail.com \\ Letícia Amanda dos Santos Silva \\ ORCID: https://orcid.org/0000-0002-7124-8391 \\ Universidade Estadual de Londrina, Brasil \\ E-mail: leticia.amanda@uel.br \\ Maria Isabel Mello Martins \\ ORCID: https://orcid.org/0000-0001-8416-2450 \\ Universidade Estadual de Londrina, Brasil \\ E-mail:imartins@uel.br \\ Maíra Planzo Fernandes \\ ORCID: https://orcid.org/0000-0002-2449-6990 \\ Universidade Estadual de Londrina, Brasil \\ E-mail: maira.planzo.fernandes@uel.br \\ Julia Rodrigues Greghi \\ ORCID: https://orcid.org/0000-0002-9596-2426 \\ Universidade Estadual de Londrina, Brasil \\ E-mail: julia.rodrigues.greghi@uel.br \\ Luana Martins de Souza Amaral \\ ORCID: https://orcid.org/0000-0001-9691-3450 \\ Universidade Estadual de Londrina, Brasil \\ E-mail: luanamsa20@gmail.com \\ Vinícius Wagner Silva \\ ORCID: https://orcid.org/0000-0001-8623-5131 \\ Universidade Estadual de Londrina, Brasil \\ E-mail:vinicius.wagner@uel.br \\ Ariel de Aguiar \\ ORCID: https://orcid.org/0000-0003-4586-864X \\ Universidade Estadual de Londrina, Brasi \\ E-mail: medvetarielaguiar@gmail.com \\ Ana Paula Frederico Rodrigues Loureiro Bracarense \\ ORCID: https://orcid.org/0000-0002-5407-2582 \\ Universidade Estadual de Londrina, Brasil \\ E-mail: anapaula@uel.br
}

\begin{abstract}
Resumo
O tumor venéreo transmissível é uma neoplasia distribuída mundialmente que acomete cães principalmente pelo contato sexual, os animais acometidos geralmente desenvolvem nódulos no trato reprodutivo inferior. As metástases são incomuns, normalmente são observadas em animais imunocomprometidos. O objetivo deste é relatar um caso de tumor venéreo transmissível em cadela disseminado pelo abdômen. A paciente apresentava uma massa única em região cranial da vagina e massas de diversos tamanhos aderidas à parede abdominal, ao mesentério e à serosa de órgãos como intestino, baço, vesícula urinária e útero, visibilizadas ao exame ultrassonográfico. Os exames complementares como a vaginoscopia e as análises citomorfológicas das massas da cavidade abdominal e em fundo de vagina foram de grande importância para o diagnóstico definitivo. O tratamento semanal com $0,5 \mathrm{mg} / \mathrm{m}^{2}$ de Sulfato de Vincristina durante sete semanas foi efetivo. A importância deste relato é a forma incomum de metástase de TVT, visto que acometia somente a serosa dos órgãos abdominais, sem comprometer a função destes.
\end{abstract}

Palavras-chave: Metástase; Sarcoma venéreo transmissível; TVT; Vincristina.

\begin{abstract}
The transmissible venereal tumor is a neoplasm distributed worldwide that affects dogs mainly through sexual contact, the affected animals usually develop nodules in the lower reproductive tract. Metastases are uncommon, usually seen in immunocompromised animals. The aim of this paper is to report a case of a transmissible venereal tumor in a female dog spread through the abdomen. The patient had a single mass in the cranial region of the vagina
\end{abstract}


Research, Society and Development, v. 10, n. 8, e0110816429, 2021

(CC BY 4.0) | ISSN 2525-3409 | DOI: http://dx.doi.org/10.33448/rsd-v10i8.16429

and masses of different sizes adhered to the abdominal wall, mesentery and serosa of organs such as intestine, spleen, urinary vesicle and uterus, visualized on ultrasound examination. Complementary tests such as vaginoscopy and cytomorphological analyzes of the masses in the abdominal cavity and in the vagina were of great importance for the definitive diagnosis. Weekly treatment with $0.5 \mathrm{mg} / \mathrm{m}^{2}$ of Vincristine Sulfate for seven weeks was effective. The importance of this report is the uncommon form of TVT metastasis, as it affected only the serosa of Organs abdominal organs, without compromising their function.

Keywords: Metastasis; Transmissible venereal sarcoma; TVT; Vincristine.

\section{Resumen}

El tumor venéreo transmisible es una neoplasia de distribución mundial que afecta a los perros principalmente a través del contacto sexual, los animales afectados suelen desarrollar nódulos en el tracto reproductivo inferior. Las metástasis son infrecuentes y generalmente se observan en animales inmunodeprimidos. El objetivo de este trabajo es reportar un caso de tumor venéreo transmisible en una perra diseminado a través del abdomen. La paciente presentaba una sola masa en la región craneal de la vagina y masas de diferentes tamaños adheridas a la pared abdominal, mesenterio y serosa de órganos como intestino, bazo, vesícula urinaria y útero, visualizadas en el examen ecográfico. Las pruebas complementarias como la vaginoscopia y los análisis citomorfológicos de las masas en la cavidad abdominal y en la vagina fueron de gran importancia para el diagnóstico definitivo. El tratamiento semanal con 0,5 $\mathrm{mg} / \mathrm{m} 2$ de sulfato de vincristina durante siete semanas fue eficaz. La importancia de este informe radica en la forma poco común de metástasis de TVT, ya que afectó solo la serosa de los órganos abdominales, sin comprometer su función.

Palabras clave: Metástasis; Sarcoma venéreo transmisible; TVT; Vincristina.

\section{Introdução}

O tumor venéreo transmissível canino (TVT), conhecido também como sarcoma venéreo transmissível (Das \& Das, 2000; Martins et al., 2005), é uma neoplasia que ocorre pela transferência de células tumorais vivas de um cão ao outro, geralmente no momento da cópula (Das \& Das, 2000; Mukaratirwa \& Gruys, 2003; Rebbeck et al., 2009). Uma vez implantadas em um novo animal, essas células se reproduzem e formam um tumor que se localiza, geralmente, nos órgãos genitais externos de machos e de fêmeas (Murchison et al., 2014; Rebbeck et al., 2009), eventualmente nos órgãos genitais internos (Martins et al., 2005) e, mais raramente, em locais extragenitais.

Os sinais clínicos variam de acordo com a localização do tumor, sendo que geralmente é observada a presença de uma ou mais massas nos órgãos genitais, secreção serosanguinolenta ou hemorrágica oriunda dos órgãos genitais e/ou das narinas e lambedura excessiva dessas regiões (Cohen, 1985; Rogers et al., 1998). Ao exame físico, o tecido tumoral apresenta-se com tamanhos variáveis, geralmente com coloração branco-acinzentada, rosada ou avermelhada; na maioria das vezes, são friáveis, hemorrágicos, com aspecto de couve-flor e, eventualmente, podem apresentar aparência necrótica (Ayala-Díaz et al., 2019; Das \& Das, 2000; Oduye et al., 1973).

Caracteriza-se como uma neoplasia de células redondas potencialmente maligna, porém, o seu crescimento e disseminação são dependentes de fatores imunológicos do hospedeiro. Geralmente não tem caráter metastático, porém, seu potencial de malignidade aumenta significativamente em animais imunossuprimidos (Cohen, 1985; Martins et al., 2005). Além da imunossupressão, os cães recém-nascidos e aqueles desnutridos apresentam maiores taxas de metástase (Park et al., 2006). A incidência de metástases relatada muitas vezes é resultado da auto ou da hetero implantação ou por extensões mecânicas dessas massas para os tecidos adjacentes, sendo incomuns metástases oriundas da via hematógena ou linfática (Das \& Das, 2000; Rodrigues et al., 2001).

O diagnóstico é realizado por meio de achados clínicos e epidemiológicos observados durante a anamnese e ao exame físico do animal, bem como, pelos exames complementares como a citopatologia e eventualmente a histologia dos tecidos acometidos. Outras técnicas diagnósticas podem ser utilizadas como a imuno-histoquímica e a técnica de reação em cadeia de polimerase (PCR) (Ganguly et al., 2013; Park et al., 2006). 
Research, Society and Development, v. 10, n. 8, e0110816429, 2021

(CC BY 4.0) | ISSN 2525-3409 | DOI: http://dx.doi.org/10.33448/rsd-v10i8.16429

Dentre as formas de tratamento, a quimioterapia com Sulfato de Vincristina e a radiação são as formas mais eficazes, mas há relatos de tratamento com outros quimioterápicos, com imunoterapia ou, em alguns casos, cirurgicamente (Ganguly et al., 2013; Rogers et al., 1998).

O objetivo deste relato é apresentar um caso incomum de tumor venéreo transmissível em uma cadela, localizado em fundo de vagina e disseminado em cavidade abdominal, que obteve tratamento efetivo com a quimioterapia com Sulfato de Vincristina.

\section{Relato de Caso}

Uma cadela, sem raça definida, com aproximadamente 10 anos de idade, pesando 6,3 $\mathrm{kg}$ foi atendida com queixa principal de anorexia, êmese e secreção vaginal purulenta. Ao exame físico o animal apresentou desidratação leve, abdômen moderadamente distendido e tenso à palpação. A inspeção vulvar/vaginal externa evidenciou secreção vaginal purulenta em grande quantidade.

Ao exame ultrassonográfico foi visibilizado útero aumentado com presença de moderada quantidade de conteúdo hipoecoico em seu lúmen, além de estruturas circulares hiperecogênicas em região dorsal à bexiga, próximas ao corpo uterino. Exames hematológicos e bioquímicos demonstraram anemia normocítica normocrômica discreta, leucocitose por neutrofilia sem desvio e trombocitopenia acentuada. Ademais, foram mensuradas creatinina, ureia, alanina aminotransferase (ALT), fosfatase alcalina (FA), proteínas totais, albumina e glicose, dentre os quais, apenas a glicose apresentava-se discretamente abaixo do valor de referência $(73 \mathrm{mg} / \mathrm{dL})$.

$\mathrm{O}$ animal foi submetido à anestesia geral inalatória para a realização de procedimento cirúrgico de celiotomia exploratória e ovariohisterectomia $(\mathrm{OH})$, no qual, foi possível visualizar ambos os cornos uterinos e o corpo do útero moderadamente aumentados, com conteúdo em seu interior e parede espessada compatível com complexo hiperplasia endometrial cística-piometra. Pequenas nodulações aderidas ao mesentério e à superfície serosa dos cornos uterinos e do intestino foram identificadas (Figura 1A). Ainda, foram visualizadas massas disseminadas pelo abdômen, de coloração esbranquiçada à rosada, com tamanhos variando de $0,3 \mathrm{~cm}$ a $8 \mathrm{~cm}$ de diâmetro, consistência fibroelástica, aderidas ao mesentério e ao peritônio que recobre o intestino, baço, vesícula urinária, cornos e corpo uterino e parede abdominal (Figura 1B). As massas tinham consistência fibroelástica e apresentavam sangramento difuso após a manipulação. 
Research, Society and Development, v. 10, n. 8, e0110816429, 2021

(CC BY 4.0) | ISSN 2525-3409 | DOI: http://dx.doi.org/10.33448/rsd-v10i8.16429

Figura 1:(A) Cornos uterinos de cadela distendidos com parede espessada. Alça intestinal, útero e mesentério apresentando pequenas nodulações róseas em serosa (setas vermelhas). (B) Múltiplas nodulações distribuídas pela cavidade abdominal. Coto uterino (seta verde); alças intestinais (seta azul).

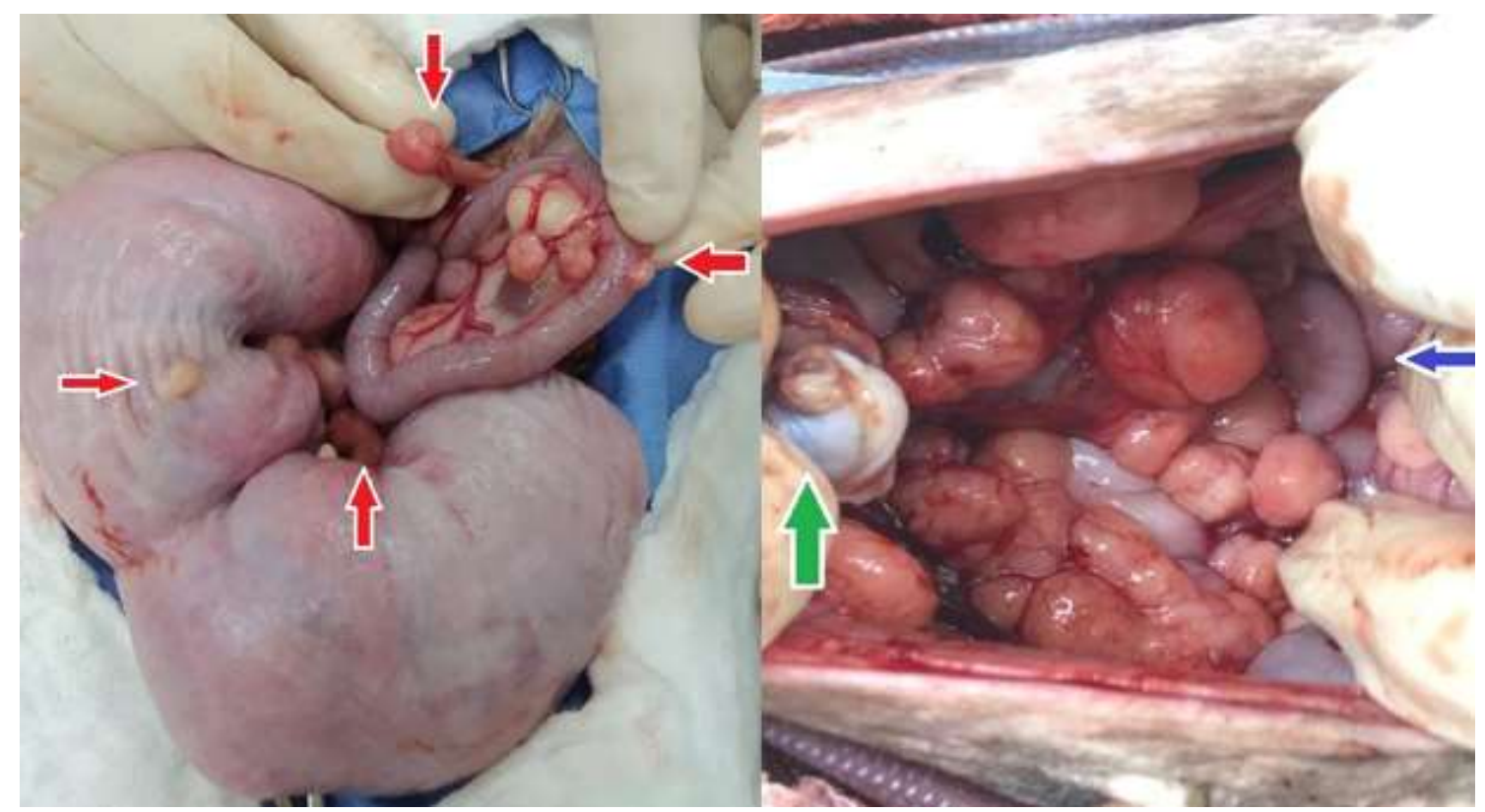

Fonte: Autores.

Fragmentos dessas massas foram retiradas e enviadas para análise histopatológica, cujo diagnostico foi TVT plasmocitoide. A histologia mostrou células arredondadas, distribuídas em cordões e em ninhos, com citoplasma moderado, indistinto e eosinofílico. O núcleo celular era arredondado, levemente basofílico; havia relação núcleo/citoplasma alta; nucléolo evidente e múltiplos grânulos de cromatina e presença de mitoses típicas e atípicas. As células eram circundadas por moderado estroma fibrovascular e havia acentuada anisocitose e anisocaríase, além de moderada quantidade de linfócitos e plasmócitos. Em um segundo fragmento da massa, também foram observados hemorragia multifocal, congestão acentuada e infiltrado inflamatório composto por neutrófilos, macrófagos e linfócitos em intensa quantidade (Figura 2). 
Research, Society and Development, v. 10, n. 8, e0110816429, 2021

(CC BY 4.0) | ISSN 2525-3409 | DOI: http://dx.doi.org/10.33448/rsd-v10i8.16429

Figura 2: Fotomicrografia de tumor venéreo transmissível demonstrando células redondas dispostas em ninhos circundados por moderado estroma fibrovascular em permeio a moderado infiltrado inflamatório linfoplasmocitário. No canto superior esquerdo observa-se foco hemorrágico. HE - 40x.

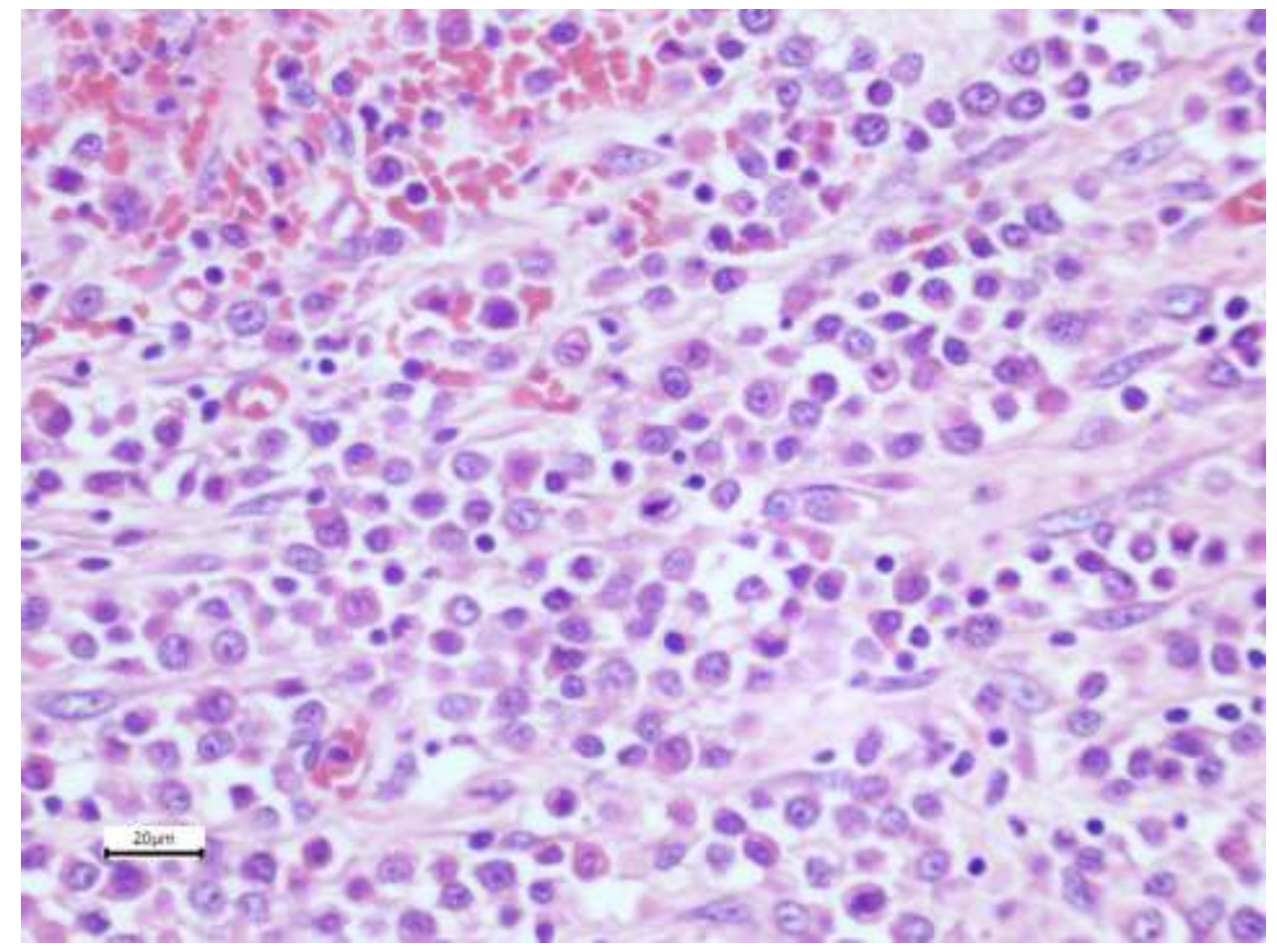

Fonte: Autores.

Após a cirurgia, o canal vaginal foi lavado com solução fisiológica e foi realizada a inspeção de vagina anterior com câmera endoscópica e espéculo de vidro (vaginoscopia), sendo observado um nódulo esbranquiçado, achatado em fundo de vagina com aproximadamente $1 \mathrm{~cm}$ de diâmetro, foi colhido material com uma escova ginecológica, e a citopatologia foi sugestivo de TVT plasmocitoide. Iniciou-se o tratamento quimioterápico com Sulfato de Vincristina na dose de $0,5 \mathrm{mg} / \mathrm{m}^{2} / \mathrm{cada}$ 7 dias durante sete semanas e o acompanhamento ultrassonográfico a cada 15 dias.

As massas abdominais eram palpáveis até a quinta semana de tratamento, porém, era evidente em ultrassonografia quinzenal, a diminuição de quantidade e de tamanho das mesmas (Figura 3). 
Research, Society and Development, v. 10, n. 8, e0110816429, 2021

(CC BY 4.0) | ISSN 2525-3409 | DOI: http://dx.doi.org/10.33448/rsd-v10i8.16429

Figura 3-a) e b) Imagem ultrassonográfica do abdômen de uma cadela no início do tratamento com Sulfato de Vincristina, evidenciando múltiplas massas em abdômen (setas), com destaque para a área caudal ao baço e em região de coto uterino; c) Imagem ultrassonográfica obtida na quinta aplicação de Sulfato de Vincristina, evidenciando massa com aproximadamente 0,6 cm de diâmetro; d) Observa-se nódulo de 0,4cm de diâmetro em região caudal ao baço de paciente canina no dia da sétima sessão de quimioterapia com Sulfato de Vincristina para tratamento de TVT intra-abdominal, em foco (seta amarela).

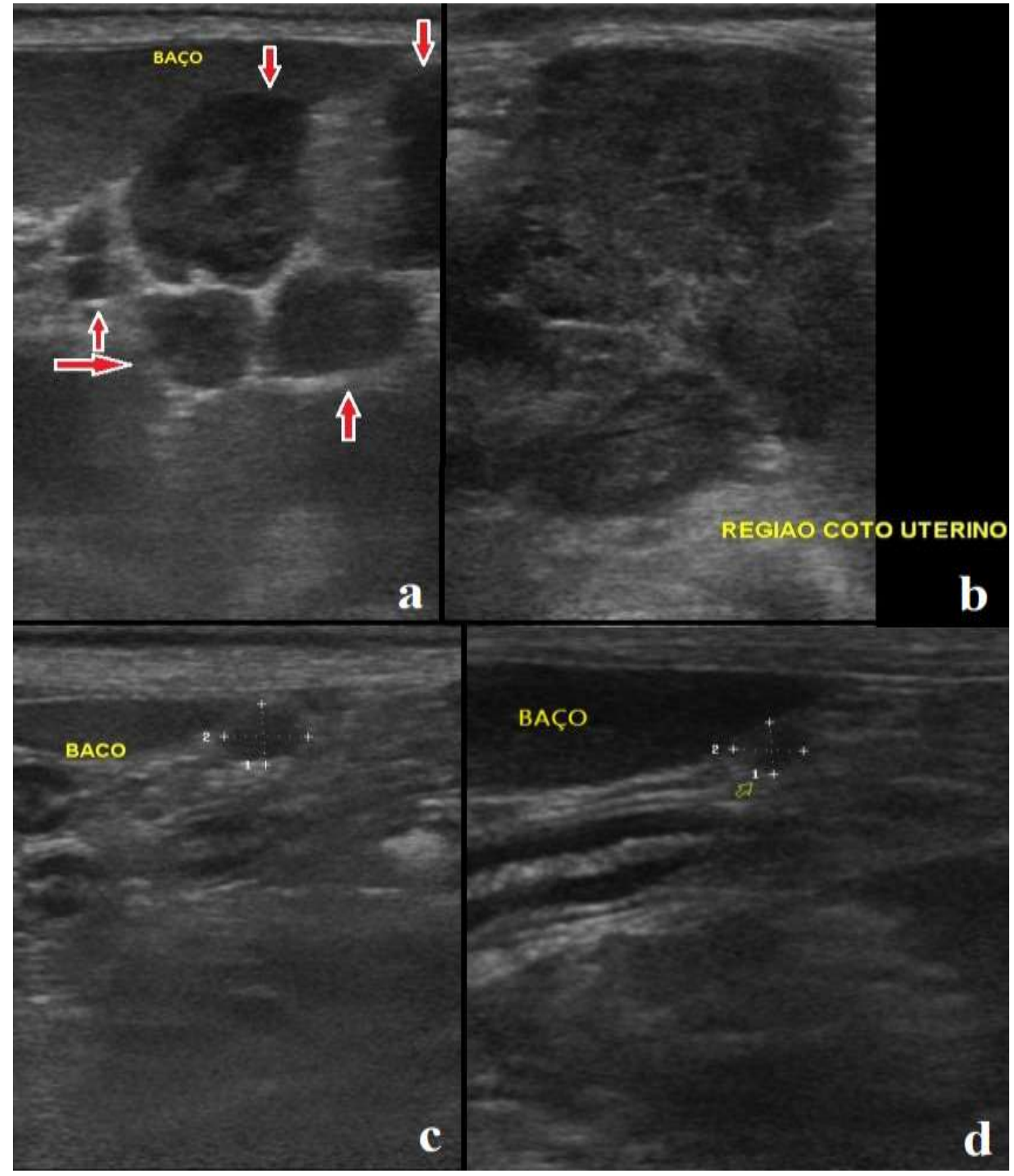

Fonte: Autores.

Em vaginoscopia realizada na sexta sessão quimioterápica não foi observado nenhuma nodulação em fundo de vagina, foi colhido material para análise citológica, e repetido a citologia vaginal após a sétima aplicação de sulfato de vincristina, e ambas foram negativas para células de TVT, mostrando eficácia da quimioterapia para o tratamento do nódulo genital. Ao fim 
Research, Society and Development, v. 10, n. 8, e0110816429, 2021

(CC BY 4.0) | ISSN 2525-3409 | DOI: http://dx.doi.org/10.33448/rsd-v10i8.16429

de sete sessões de quimioterapia, foram realizados mais quatro exames ultrassonográficos, com intervalo de 15 dias, durante os quais não foram observados nódulos, evidenciando o sucesso no tratamento das massas abdominais com sulfato de vincristina.

Durante o tratamento com Sulfato de Vincristina, a paciente apresentou sintomas como êmese, hiporexia, tenesmo, dor abdominal, trombocitopenia, leucopenia e neutropenia, que foram tratados sem impedir a continuidade do protocolo quimioterápico.

\section{Discussão}

A paciente apresentava TVT plasmocitóide disseminado em cavidade abdominal, afetando a superfície serosa de útero, da vesícula urinária, do intestino, do baço, da parede abdominal e afetando o mesentério, além de nodulação em fundo de vagina. O tumor venéreo transmissível geralmente acomete os órgãos genitais externos de machos e de fêmeas (Murchison et al., 2014; Rebbeck et al., 2009), mas também podem afetar os órgãos genitais internos (Martins et al., 2005). Além disso, locais extragenitais podem ser afetados, como a mucosa oral, nasal e a ocular; pele; linfonodos; reto; baço; fígado; glândulas mamárias; pulmões; costelas; mediastino; rins e cérebro (Chikweto et al., 2013; Ganguly et al., 2013; Setthawongsin et al., 2016).

Acredita-se que a lesão inicial ocorreu por meio do contato sexual com cão portador de TVT e, que após isso, se disseminou, provavelmente por via hematógena, por todo o mesentério na superfície serosa dos órgãos, pois segundo a literatura as metástases geralmente ocorrem por extensão mecânica ou resultado de hetero ou de autoimplantação, sendo que as vias hematógena e linfática são incomuns (Das \& Das, 2000; Rodrigues et al., 2001).

A paciente em questão possuía 10 anos, corroborando com estudos em que a idade avançada foi relacionada ao surgimento de metástases (Setthawongsin et al., 2019). As metástases também ocorrem com frequência em animais imunocomprometidos, desnutridos ou recém-nascidos (Cohen, 1985; Park et al., 2006),

Estudos descrevem que a metástase de TVT é incomum, podendo ocorrer em $5 \%$ a $25 \%$ dos casos e que $10,3 \%$ dos casos de TVT linfocítico apresentam massas não primárias contra $41 \%$ em casos do tipo plasmocítico, sugerindo que o tipo plasmocitóide tem maior capacidade para desenvolver metástases (Amaral et al., 2007; Kabuusu et al., 2010). Porém, Paranzini et al. (2015) não observaram relação com o tipo citomorfológico e a resistência do tumor ao sulfato de vincristina ou ao número de sessões necessárias para a regressão do tumor.

Poucos são os estudos que relatam a neoplasia em abdômen disseminada pelo mesentério e em superfície serosa de vísceras sem o comprometimento desses órgãos. Trevizan et al. (2012) relataram um caso no qual o animal apresentou TVT disseminado em omento, fígado, baço, útero e peritônio de parede abdominal sem neoformação em genital externa, porém, relataram comprometimento de parênquima hepático e esplênico.

O animal do caso em questão apresentava abdômen distendido causado pelo aumento de volume uterino, devido ao quadro de piometra e pela grande quantidade de massas no interior do abdômen. O diagnóstico de TVT foi um achado durante a investigação e andamento do caso clínico, porém deve ser incluído no protocolo de pacientes diagnosticados com TVT a ultrassonografia abdominal para avaliação abdominal em busca de metástases.

Apesar da quimioterapia com Sulfato de Vincristina ser um método eficaz para tratamento de TVT, pode ocorrer resistência ou recidiva após o término do protocolo (Faccini et al., 2019; Setthawongsin et al., 2016). Durante dois meses foi realizado o acompanhamento ultrassonográfico e não foram visibilizadas alterações compatíveis com metástases. Rogers et al. (1998) em seu estudo observou a ocorrência de recidiva oito meses após o tratamento com Vincristina. Atualmente, oito meses após o término do tratamento, o animal encontra-se clinicamente bem, sem sinais de recidiva. 
Research, Society and Development, v. 10, n. 8, e0110816429, 2021

(CC BY 4.0) | ISSN 2525-3409 | DOI: http://dx.doi.org/10.33448/rsd-v10i8.16429

Devido aos efeitos colaterais observados em protocolos quimioterápicos com Sulfato de Vincristina, torna-se necessária, além da avaliação do estado geral do animal em cada sessão, a coleta de sangue para realização de hemograma completo. Dentre os efeitos adversos encontrados no presente caso, a maioria foi também observada por outros autores. Ganguly et al. (2013) citam anorexia parcial e depressão leve dentro de um a dois dias após a administração do fármaco, bem como leucopenia transitória em menos de $2 \%$ dos cães tratados com Sulfato de Vincristina. Podendo, em alguns casos ser necessária a associação com agentes antibióticos ou até mesmo a interrupção temporária do tratamento por uma a duas semanas.

\section{Conclusão}

Perante este relato de caso, torna-se importante destacar o diagnóstico incomum de tumor venéreo transmissível em fundo de vagina com metástases disseminadas pela superfície serosa de órgãos abdominais, bem como, ressaltar o sucesso no tratamento com o protocolo quimioterápico utilizando $0,5 \mathrm{mg} / \mathrm{m}^{2}$ de Sulfato de Vincristina semanalmente, durante sete semanas. Com base nisso e levando em consideração os achados de outros autores sobre os riscos de metástase desse tipo tumoral, torna-se evidente a necessidade de exames complementares de imagem, visto que esse tipo tumoral pode causar massas primárias ou metástases intra-abdominais não detectáveis durante o exame físico habitual.

\section{Referências}

Amaral, A. S. do, Bassani-Silva, S., Ferreira, I., Santos Da Fonseca, L., Evangelista De Andrade, F. H., Fernando, L., Gaspar, J., \& Sousa Rocha, N. (2007). Cytomorphological characterization of transmissible canine venereal tumor Caracterização citomorfológica do tumor venéreo transmissível canino. 102, $563-564$.

Ayala-Díaz, S., Jiménez-Lima, R., Ramírez-Alcántara, K. M., Lizano, M., Castro-Muñoz, L. J., Reyes-Hernández, D. O., Arroyo-Ledezma, J., \& ManzoMerino, J. (2019). Presence of Papillomavirus DNA sequences in the canine transmissible venereal tumor (CTVT). PeerJ, 2019(10), 1-14. https://doi.org/10.7717/peerj.7962

Chikweto, A., Kumthekar, S., Larkin, H., Deallie, C., Tiwari, K. P., Sharma, R. N., \& Bhaiyat, M. I. (2013). Genital and Extragenital Canine Transmissible Venereal Tumor in Dogs in Grenada, West Indies. Open Journal of Veterinary Medicine, 03(02), 111-114. https://doi.org/10.4236/ojvm.2013.32018

Cohen, D. (1985). The Canine Transmissible Venereal Tumor: A Unique Result of Tumor Progression. In Advances in Cancer Research (Vol. 43, Issue C). https://doi.org/10.1016/S0065-230X(08)60943-4

Das, U., \& Das, A. K. (2000). Review of canine transmissible venereal sarcoma. Veterinary Research Communications, 24(8), 545-556. https://doi.org/10.1023/A:1006491918910

Faccini, L. S., Legramanti, W. M., de Castro, L. T., Coelho, A. C. B., Teixeira, M. C., Shild, A. L., \& Pereira, C. M. (2019). Multiple metastases of a transmissible venereal tumor in a dog. Acta Scientiae Veterinariae, 47(November), 1-5. https://doi.org/10.22456/1679-9216.97399

Ganguly, B., Das, U., \& Das, A. K. (2013). Canine transmissible venereal tumour: A review. Veterinary and Comparative Oncology, 14(1), 1-12. https://doi.org/10.1111/vco.12060

Kabuusu, R. M., Stroup, D. F., \& Fernandez, C. (2010). Risk factors and characteristics of canine transmissible venereal tumours in Grenada, West Indies. Veterinary and Comparative Oncology, 8(1), 50-55. https://doi.org/10.1111/j.1476-5829.2009.00204.x

Martins, M. I. M., Londrina, U. E. De, Souza, F. F., \& Gobello, C. (2005). The Canine Transmissible Venereal Tumor : Etiology , Pathology, Diagnosis and Treatment In: Recent Advances in Small Animal Reproduction, Concannon P. W ., England G ., Verstegen III J . The Canine Transmissible Venereal Tumor: Etiology, Pathology, . 25 April 2005.

Mukaratirwa, S., \& Gruys, E. (2003). Canine transmissible venereal tumour: Cytogenetic origin, immunophenotype, and immunobiology. A review. Veterinary Quarterly, 25(3), 101-111. https://doi.org/10.1080/01652176.2003.9695151

Murchison, E. P., Wedge, D. C., Alexandrov, L. B., Fu, B., Martincorena, I., Ning, Z., Tubio, J. M. C., Werner, E. I., Allen, J., De Nardi, A. B., Donelan, E. M., Marino, G., Fassati, A., Campbell, P. J., Yang, F., Burt, A., Weiss, R. A., \& Stratton, M. R. (2014). Transmissible dog cancer genome reveals the origin and history of an ancient cell lineage. Science, 343(6169), 437-440. https://doi.org/10.1126/science.1247167

Oduye, O. O., IKEDE, B. O., ESURUOSO, G. O., \& AKPOKODJE, J. U. (1973). Metastatic transmissible venereal tumour in dogs. Journal of Small Animal Practice, 14(10), 625-649. https://doi.org/10.1111/j.1748-5827.1973.tb06399.x

Paranzini, C. S., Sant'anna, M. C., Di Santis, G. W., \& Martins, M. I. M. (2015). Prevalence of different cytomorphological types of transmissible venereal tumours and the association with prognosis in dogs treated with vincristine sulphate - Retrospective study. Semina:Ciencias Agrarias, 36(6), 3795-3800. 
Research, Society and Development, v. 10, n. 8, e0110816429, 2021

(CC BY 4.0) | ISSN 2525-3409 | DOI: http://dx.doi.org/10.33448/rsd-v10i8.16429

https://doi.org/10.5433/1679-0359.2015v36n6p3795

Park, M. S., Kim, Y., Kang, M. S., Oh, S. Y., Cho, D. Y., Shin, N. S., \& Kim, D. Y. (2006). Disseminated transmissible venereal tumor in a dog. Journal of Veterinary Diagnostic Investigation, 18(1), 130-133. https://doi.org/10.1177/104063870601800123

Rebbeck, C. A., Thomas, R., Breen, M., Leroi, A. M., \& Burt, A. (2009). Origins and evolution of a transmissible cancer. Evolution, 63(9), 2340-2349. https://doi.org/10.1111/j.1558-5646.2009.00724.x

Rodrigues, G. N., Alessi, A. C., \& Laus, J. L. (2001). Intraocular Transmissible Venereal Tumor in a Dog. Ciência Rural, 31(1), 141-143. https://doi.org/10.1590/s0103-84782001000100023

Rogers, K. S., Walker, M. A., \& Dillon, H. B. (1998). Transmissible venereal tumor: A retrospective study of 29 cases. Journal of the American Animal Hospital Association, 34(6), 463-470. https://doi.org/10.5326/15473317-34-6-463

Setthawongsin, C., Techangamsuwan, S., Tangkawattana, S., \& Rungsipipat, A. (2016). Cell-based polymerase chain reaction for canine transmissible venereal tumor (CTVT) diagnosis. Journal of Veterinary Medical Science, 78(7), 1167-1173. https://doi.org/10.1292/jvms.15-0710

Setthawongsin, C., Teewasutrakul, P., Tangkawattana, S., Techangamsuwan, S., \& Rungsipipat, A. (2019). Conventional-Vincristine Sulfate vs. Modified Protocol of Vincristine Sulfate and L-Asparaginase in Canine Transmissible Venereal Tumor. Frontiers in Veterinary Science, 6(September), 1-12. https://doi.org/10.3389/fvets.2019.00300

Trevizan, J. T., Carreira, J. T., Souza, N. C., Carvalho, I. R., Gomes, P. B. C., Lima, V., Orlandi, C. M. B., Rozza, D. B., \& Koivisto, M. B. (2012). Disseminated Transmissible Venereal Tumour Associated With Leishmaniasis in a Dog. Reproduction in Domestic Animals, 47(SUPPL. 6), 356-358. https://doi.org/10.1111/rda.12110 